\title{
Pathophysiological and clinical aspects of breathing after stroke
}

\author{
R S Howard, A G Rudd, C D Wolfe, A J Williams
}

Stroke may disrupt breathing either by (A) causing a disturbance of central rhythm generation, (B) interrupting the descending respiratory pathways leading to a reduced respiratory drive, or (C) causing bulbar weakness leading to aspiration.

\section{Pathophysiology of respiratory control in stroke}

Neural control of respiration in man depends on a central drive to the respiratory muscles which is modulated by chemical and mechanical inputs. ${ }^{1}$ While many of the factors controlling established respiratory rhythm in mammals are understood, the neural mechanisms of rhythm generation remain obscure..$^{2-4}$ It has proved difficult, in man, to attribute precise respiratory function to localised anatomical substrates because lesions are rarely localised and coexisting pulmonary, cardiovascular, or autonomic influences may complicate the clinical picture. Furthermore accurate diagnosis of respiratory insufficiency has led to earlier therapeutic intervention with controlled ventilation. Also there is probably considerable redundancy and plasticity of the neural substrate of respiratory control, thus congenital, longstanding, or slowly progressive and destructive mass lesions can have little or no functional consequence while acute discrete lesions in a similar distribution may lead to profound respiratory impairment. Finally much of the literature is flawed because the extensive experimental animal work has been applied to man without any evidence for anatomicophysiological correlates. However in individual case studies abnormalities of respiration may be associated with small, discrete lesions of the central nervous system, defined by imaging or postmortem, particularly due to stroke. Such reports have complemented experimental animal work and have greatly increased our understanding of the mechanisms that control breathing in man.

Central respiratory drive is mediated by three pathways, which are largely anatomically and functionally independent above the segmental level, ${ }^{1}$ although it is increasingly clear that these systems must interact with one another to some extent. ${ }^{56}$

Lane Fox Unit, St

Thomas' Hospita

Trust, London

A J Williams

Correspondence to: Dr Robin Howard, Department of Neurology, St Thomas' Hospital, Guy's and St Thomas' Hospital Trust, Lambeth Palace Road, London SE1 7EH, UK

Submitted 2 April 2001 Accepted 15 May 2001 pons and medulla in the region of the nucleus tractus solitarius and nucleus retroambigualis (for review see Howard and Hirsch ${ }^{7}$ ). As a consequence of lesions in this area automatic respiratory control is disrupted; the patient is voluntarily able to maintain his respiratory pattern and breathes normally while awake and alert but during sleep there is a sudden or progressive decline in tidal volume and respiratory rate culminating in central apnoea.

Abnormal patterns of rate and rhythm are also often a reflection of impaired automatic ventilatory control. ${ }^{8}$ Primary central neurogenic hyperventilation is a rare condition characterised by rapid, regular hyperventilation which persists in the face of alkalosis, raised oxygen tension, low carbon dioxide tension, and in the absence of any pulmonary or airway disorder. ${ }^{9}{ }^{10}$ However, hyperventilation in the poststroke patient is common but is due to intrinsic pulmonary involvement. ${ }^{11-13}$ In apneustic breathing there are sustained inspiratory cramps with a prolonged pause at full inspiration or alternating brief end inspiratory and expiratory pauses. The pattern has been associated with bilateral tegmental infarcts in the pons. Ataxic respiration is characterised by a completely irregular respiratory cycle of variable frequency and tidal volume alternating with periods of apnoea. It is particularly associated with medullary impairment either due to brainstem stroke or compression due to rapidly expanding lesions and may be an important sign of impending respiratory arrest. Hiccups consist of brief bursts of intense inspiratory activity involving the diaphragm and inspiratory intercostal muscles with reciprocal inhibition of the expiratory intercostals. ${ }^{14}{ }^{15}$ Glottic closure occurs almost immediately after the onset of diaphragmatic contraction thus minimising the ventilatory effect. Intractable hiccups may be the result of structural or functional disturbances of the medulla or its afferent or efferent connections with the respiratory muscles This may be associated with structural lesions of the medulla including infarction in the territory of the posterior inferior cerebellar artery. The development of hiccups in this context may anticipate the development of irregularities of the respiratory rhythm culminating in respiratory arrest.

BEHAVIOURAL (VOLUNTARY) RESPIRATION Behavioural (voluntary) respiration operates during wakefulness and allows voluntary modulation of respiration in response, for example, to speaking, singing, breath holding, and straining. Volitional control is active during consciousness but quiescent during sleep, although it may be involved in the chaotic respiratory patterns seen during rapid eye movement sleep. Voluntary control may be impaired by bilateral lesions affecting the descending 
corticospinal or corticobulbar tracts, ${ }^{5}$ and is particularly seen in association with destructive vascular lesions of the basal pons or of the medullary pyramids and adjacent ventromedial portion which may result in the "locked in" syndrome. ${ }^{16}$ Selective interruption of the voluntary pathways in man leads to a strikingly regular and unvarying respiratory pattern during wakefulness as well as sleep, with loss of the ability to take a deep breath, hold the breath, cough voluntarily, or initiate any kind of volitional respiratory movement. The tidal volume remains responsive to carbon dioxide and a reflex cough is preserved. ${ }^{17}$ Diffuse cortical vascular disease may lead to selective abnormalities of voluntary breathing such that there is an inability to take a deep breath or to hold the breath to command. These respiratory apraxias may be associated with inability to initiate voluntary swallowing or with other behavioural apraxias. ${ }^{18}$ Cheyne-Stokes respiration is characterised by a smooth waxing and waning of breath volume and frequency separated by periods of apnoea ${ }^{19}{ }^{20}$; the hyperpnoeic phase is longer than the apnoea and the entire cycle typically lasts one minute or more. The respiratory oscillations are associated with phasic changes in cerebral blood flow, cerebrospinal fluid pressure, arterial and alveolar oxygen and carbon dioxide, level of alertness and pupillary size; periodic heart block and ventricular arrhythmias are also common. It has been suggested that Cheyne-Stokes respiration may occur in up to $50 \%$ of patients after unilateral supratentorial stroke ${ }^{21} 22$ and, despite the observations of Plum and Posner, it may also be common after infratentorial stroke. Studies in these patients show the frequency variations of respiratory amplitude modulation is low suggesting that Cheyne-Stokes respiration represents a relatively uniform response to central nervous system injury regardless of infarct size or location. During Cheyne-Stokes respiration there are concomitant periodic drops in arterial oxygen saturation compromising the vulnerable hypoperfused peri-infarct tissue of the ischaemic penumbra.

LIMBIC (EMOTIONAL) RESPIRATION

Limbic (emotional) respiration accounts for the preservation of respiratory modulation to emotional stimuli including laughing, coughing, and anxiety despite loss of voluntary control. This implies that descending limbic influences on automatic respiration are anatomically and functionally independent of the voluntary respiratory system. Munschauer et al described a patient with locked in syndrome due to infarction of the basal pons, this led to loss of voluntary control but carbon dioxide responses remained normal. ${ }^{23}$ This patient showed preserved respiratory modulation to emotional stimuli including coughing and anxiety and in another patient laughing. ${ }^{17}$ Such an independent descending pathway, mediating limbic control of respiration lies either in the pontine tegmentum or lateral basis pontis. Such limbic pathways are also suggested by the effect of limbic cortex stimulation and epileptic seizures.
Patterns of respiratory impairment due to stroke

CORTEX

Hemispheric ischaemic strokes influence respiratory function to a modest degree. Reductions of both chest wall and diaphragm excursion contralateral to the stroke have been reported. $^{24} 25$ The latter association correlates well with the localisation of the diaphragm cortical representation found by transcranial magnetic stimulation and positron emission tomography scanning. ${ }^{26-31}$ At present there is no clear evidence of cerebral dominance for diaphragm function.

Patients with bilateral hemispheric cerebrovascular disease show an increased respiratory responsiveness to carbon dioxide and are liable to develop Cheyne-Stokes respiration suggesting disinhibition of lower respiratory centres. Such a response may persist months to years after the stroke. Diffuse cortical vascular disease may also lead to a selective inability of voluntary breathing (respiratory apraxia). ${ }^{18}$ Intermittent upper airway obstruction and apnoea due to periodic fluctuations in the position of the vocal cords is associated with cortical supranuclear palsy due to bilateral lesions of the operculum. ${ }^{32}$

\section{BRAINSTEM}

The effects of brainstem dysfunction on respiration depend on the pathology, localisation, and speed of onset of the lesion. In patients with bulbar lesions, particularly vascular, the combination of impaired swallow, abnormalities of the respiratory rhythm, reduced vital capacity, and reduced or absent triggering of cough reflex all increase the risk of aspiration pneumonia. ${ }^{33}$ Nocturnal upper airway occlusion may also contribute to respiratory impairment. Unilateral or bilateral lateral tegmental infarcts in the pons (at or below the level of the trigeminal nucleus) may lead to apneustic breathing and impairment of carbon dioxide responsiveness, ${ }^{34}$ while similar lesions in the medulla (for example, lateral medullary syndrome) may result in acute failure of the automatic respiration. ${ }^{35}{ }^{36}$ Infarction of the basal pons (locked in syndrome) or of the pyramids and the adjacent ventromedial portion of the medulla may lead to complete loss of the voluntary system with a highly regular breathing pattern but a complete inability to initiate any spontaneous respiratory movements. ${ }^{37}$

Acute vascular lesions in the lower brainstem compromise respiratory control, particularly during sleep, leading to irregularities of rate and rhythm of breathing which lead to Cheyne-Stokes respiration, hypopnoea, and obstructive apnoea. ${ }^{38}{ }^{39}$ It is likely that size and bilaterality of the lesions determine the type and severity of abnormalities of the respiratory pattern. In a series of 15 patients with vascular lesions of the lower brainstem, patients with unilateral lesions in the rostrolateral medulla showed a reduced ventilatory sensitivity to inhaled carbon dioxide. In these patients there was a minimal effect on breathing while awake, at rest or during exertion, however there was a 
high incidence of fragmented sleep and obstructive sleep apnoea associated with hypoxaemia. The authors concluded that patients with unilateral rostrolateral medullary lesions require monitoring during sleep to diagnose sleep apnoea. ${ }^{38}$

Isolated central sleep apnoea due to brainstem vascular disease is usually associated with bilateral lesions caudal to the $\mathrm{V}$ cranial nerve in the pons down to the ventral lateral, tegmental pons, medulla, and cervical spinal cord. Occasional reports have described central apnoea with unilateral lesions involving nucleus ambiguus but sparing nucleus tractus solitarius; however the relevance of these is difficult to assess with limited respiratory, imaging, and neuropathological information. ${ }^{39}$

CERVICAL CORD

Infarction of the spinal cord at high cervical levels may selectively affect respiratory control. $^{4041}$ Lesions of the anterior pathways, particularly descending reticulospinal, lead to loss of automatic control and sudden nocturnal death from apnoea while involvement of the dorsolateral corticospinal tracts may lead to automatic respiration of the type described earlier. Infarction of the spinal cord at high cervical levels is usually due to occlusion of the anterior spinal artery and may be due to fibrocartilaginous embolism. ${ }^{42}$ Patients may present with neck or shoulder pain but then develop a rapidly evolving tetraplegia and respiratory insufficiency culminating in respiratory arrest. Complete anterior spinal artery occlusion causing infarction that extends up to $\mathrm{C} 1$ has a poor outlook, while incomplete occlusion at C3/4 may show significant recovery of respiratory and limb function. ${ }^{43}$

Respiration is commonly affected after stroke and the pattern of breathing may reflect the aetiology, localisation, and severity of the underlying cerebrovascular disease. However, the extent to which abnormal patterns of breathing after stroke may be of prognostic significance and the optimum management of post-stroke ventilatory sufficiency remain uncertain.

Funding of the South London Stroke Register from the NHS Executive, Northern and Yorkshire Region, UK, Cardiovascula Disease and Stroke programme.

1 Plum E. Neurological integration of behavioural and metabolic control of breathing. In: Parker R, ed. Breathing. Hering-Breuer centenary symposium. Churchill: London, 1970: $314-26$

2 Monteau R, Hilaire G. Spinal respiratory neurons. Progress Neurobiol 1991;37:83-144.

3 Richter DW, Mironov SL, Busselburg D, et al. Respiratory rhythm generation: plasticity of a neuronal network. Neuroscientist 2000;6:181-98.

4 Bianchi AL, Denavit-Saubié M, Champagnat J. Central control of breathing in mammals: neuronal circuitry, memcontrol of breathing in mammals: neuronal circuitry, mem-
brane properties and neurotransmitters. Physiol Rev 1995; brane prope

5 75:1-45. cal involvement in the ventilatory response to inhaled $\mathrm{CO}_{2}$ in conscious man. F Physiol 1990;420:1-18.

6 Orem J, Netick A. Behavioral control of breathing in the cat. Brain Res 1986;366:238-53.

7 Howard RS, Hirsch NP. The neural control of respiratory and cardiovascular function. In: Crockard A, Hayward R, Hoff JT, eds. Neurosurgery - the scientific basis of clinical practice. Oxford: Blackwell Scientific Publications, 2000: 289309.
8 Plum F, Posner JB. Posthyperventilation apnoea. In: Plum F, Posner JB, eds. Diagnosis of stupor and coma. 3rd Ed. Posner JB, eds. Diagnosis of stupor

9 Rodriguez M, Beale PL, Marsh HM, et al. Central neurogenic hyperventilation in an awake patient with brainstem astrocytoma. Ann Neurol 1982;11:625-8.

10 Pauzner R, Mouallem M, Sadeh M, et al. High incidence of primary cerebral lymphoma in tumour-induced central neurogenic hyperventilation. Arch Neurol 1989;46:510-12.

11 Mazzara JT, Ayres SM, Grace WJ. Extreme hypocapnia in the critically ill patient. Am 7 Med 1974;56:450-6.

12 North JB, Jennett S. Abnormal breathing patterns associated with acute brain damage. Arch Neurol 1974;31:338-44.

13 Leigh RJ, Shaw DA. Rapid, regular respiration in unconscious patients. Arch Neurol 1976;33:356-61.

14 Newsom Davis J. An experimental study of hiccup. Brain 1970;93:851-72

15 Howard RS. The causes and treatment of intractable hiccups. BMF 1992;305:1237-8.

16 Patterson JR, Grabois M. Locked in syndrome: a review of 139 cases. Stroke 1986;17:758-65.

17 Heywood P, Murphy K, Corfield DR, et al. Control of breathing in man; insights from the "locked-in" syndrome. Respir Physiol 1996;106:13-20

18 Hebertson WM, Talbert OR, Cohen ME. Respiratory apraxia and anosogosia. Trans Am Neurol Assoc 1959;84: $176-9$

19 Tobin MJ, Snyder JV. Cheyne-Stokes respiration revisited. Controversies and implications. Crit Care Med 1984;12: $882-7$

20 Naughton MT. Pathophysiology and treatment of CheyneStokes respiration. Thorax 1998;53:514-18

21 Lee MC, Klassen AC, Resch JA. Respiratory pattern disturbances in ischaemic cerebrovascular disease. Stroke 1974;5: 612-16.

22 Nachtmann A, Siebler M, Rose G. Cheyne-Stokes respiration in ischaemic stroke. Neurology 1995;45:820-1

23 Munschauer FE, Mador MJ, Ahuja A, et al. Selective paralysis of voluntary but not limbically influenced automatic respiration. Arch Neurol 1991;48:1190-2.

24 Houston JG, Morris AD, Grosset DG, et al. Ultrasonic evaluation of movement of the diaphragm after acute cerebral infarction. I Neurol Neurosurg Psychiatry 1995;58: $738-41$

25 Cohen E, Mier A, Heywood P, et al. Diaphragmatic movement in hemiplegic patients measured by ultrasonography. Thorax 1994;49:890-5.

26 Gandevia SC, Rothwell JC. Activation of the human diaphragm from the motor cortex. F Physiol 1987;384:10918.

27 Macefield G, Gandevia SC. The cortical drive to human respiratory muscles in the awake state assessed by premotor cerebral potentials. F Physiol 1991;439:545-58.

28 Colebach JG, Adams L, Murphy K, et al. Regional cerebral blood flow during volitional breathing in man. I Physiol 1991:443:91-103.

29 Maskill D, Murphy K, Mier A, et al. Motor cortical representation of the diaphragm in man. $\mathcal{F}$ Physiol 1991;443: $105-21$.

30 Ramsay SC, Adams L, Murphy K, et al. Regional cerebral blood flow during volitional expiration in man: a comparison with volitional inspiration. $\mathcal{F}$ Physiol 1993;461:85-93.

31 Similowski T, Straus C, Attali V, et al. Assessment of the motor pathway to the diaphragm usingcortical and cervical magnetic stimulation in the decision making process of phrenic pacing. Chest 1996;110:1551-7.

32 Besson G, Bogousslavsky J, Regle F, et al. Acute pseudobulbar or suprabulbar palsy. Arch Neurol 1991;48:501-7.

33 Howard RS, Williams AJ. Chronic respiratory failure of neurogenic origin. In: Miller DH, Raps EC, eds. Neurological intensive care. Oxford: Butterworth-Heinemann, 1999: 249-79.

34 Stewart J, Howard RS, Rudd AG, et al. Apneustic breathing provoked by limbic influences. Postgrad Med 7 1996;72:55961.

35 Levin BE, Margolis G. Acute failure of automatic respiration secondary to a unilateral brainstem infarct. Ann Neurol 1977;1:583-6.

36 Bogousslavsky J, Khurana R, Deruaz JP, et al. Respiratory failure and unilateral caudal brainstem infarction. Ann Neurol 1990;28:668-73.

37 Bogousslavsky J, Khurana R, Deruaz JP, et al. Respiratory failure and unilateral caudal brainstem infarction. Ann Neurol 1990;28:668-73.

38 Devereaux MW, Keane JR, Davis RL. Automatic respiratory failure associated with infarction of the medulla. Arch Neurol 1973;29:46-52.

39 Askenasy JJM, Goldhammer I. Sleep apnoea as a feature of bulbar stroke. Stroke 1988;19:637.

40 Nathan PW. The descending respiratory pathway in man. $f$ Neurol Neurosurg Psychiatry 1963;26:487-99.

41 Cheshire WP, Santos CC, Massey EW, et al. Spinal cord infarction: etiology and outcome. Neurology 1996;47:32130.

42 Srigley JR, Lambert CD, Bilbao JM, et al. Spinal cord infarction econdary to intervertebral disc embolism. Ann Neurol 1981;9:296-300

43 Howard RS, Thorpe J, Barker R, et al. Respiratory Neurol Neurosurg Psychiatry 1998;64:358-62. 